\title{
Dynamic Response of Composite Plate Subjected to Sudden Heat Flux
}

\author{
Salih N. Akour ${ }^{1}$ \\ ${ }^{1}$ Mechanical Engineering Department, School of Engineering, The University of Jordan, Amman, Jordan \\ Correspondence: Dr. Salih Akour, Mechanical Engineering Department, School of Engineering, The University \\ of Jordan, Amman 11942, Jordan. E-mail: akour@ju.edu.jo
}

Received: October 24, 2017

Accepted: November 15, 2017 Online Published: November 21, 2017

doi:10.5539/mas.v11n $12 \mathrm{p} 36$

URL: https://doi.org/10.5539/mas.v11n12p36

\begin{abstract}
Composite plates' subjected to sudden surface heating is investigated. Simply supported boundary conditions along the four sides of the plat are considered. The effect of plate thickness and stacking sequence on the maximum deflection that is induced by the thermal heat flux for a graphite-epoxy composite plate is studied using finite element analysis. Symmetric angle ply laminates plate shows least deformation compared the other stacks of the same thickness.
\end{abstract}

Keywords: thermally induced vibrations, composite laminates, FEM

\section{Introduction}

Spacecraft usually has large and flexible appendages that carry solar arrays which are connected to its main platform. This structure is subjected to sudden temperature changes at the day-night or night-day transitions in the spacecraft's orbit. Thermally induced vibrations may take place due to rapid heat flux change on the flexible appendages. In the sunlight region, solar radiation leads to temperature gradient through the appendage cross-section, consequently resulting in thermo-elastic deformation and structural dynamics. Thermally induced dynamics may occur more easily in the low earth orbit due to orbital transition time, for examples, the Orbiting Geophysical Observatories series satellites experienced such failure in the 1960s. Hubble Space Telescope observed a pointing "jitter" after launch. Such undesirable motions can reduce the operational time of the system (Thornton \& Foster, 1992). Future spacecraft will be very large, and thus, more susceptible to adverse thermally induced displacements.

The increasing use of composite structures in these high performance vehicles is due to their ability to be custom-designed in terms of directional flexure and strength. This issue attracted many researchers over the globe try to come up with best designs for such structure. (Young, 1950) derived a procedure based on the Ritz method for obtaining approximate solutions for the frequencies and modes of vibration of thin elastic plates. (Boley \& Barber, 1957) discovered that the role of inertia was important for rapidly heated plates. A solution for the simply supported and uniformly loaded rectangular plates based on a derivation by M. Levy was published by (Timoshenko \& Krieger, 1959). In that same year, (Carslaw \& Jaeger, 1959) derived an equation for a plate with one side insulated and the other side subjected to a heat rise based on one-dimensional Laplace solution. Their models for the thermal effects of composite in plates was adopted by many researches in the years to follow.

Disregarding thermoelastic coupling is justifiable according to (Boley \& Weiner, 1960) when thermoelastic dissipation is not of primary interest. (Jadeja \& Loo, 1974) studied the thermally induced vibration of a rectangular plate with one edge fixed and the other three edges simply supported. Using the thin-plate theory (Kao \& Pao, 1976) developed the governing equations for the transverse deflections of a simply supported rectangular, heterogeneous, anisotropic plate subjected to rapid heating at its top surface.

By utilizing the Classical Lamination Theory (CLT), (Wu \& Tauchert, 1980) used the Levy type solution to study thermally induced deformations and stress resultants in symmetric laminated plates. Dynamic response model for orthotropic plates exposed to rapid heat rise on one side of the plate was developed by (T. R. Tauchert, 1989; $\mathrm{Wu} \&$ Tauchert, 1980). By the superposition of two displacement fields; the quasi-static and dynamic displacements, the total displacement was obtained. An exact Levy-type solution was derived for the quasi-static 
portion. A Laplace transform was used to derive the dynamic solution. This model was later expanded by (T. R Tauchert, 1990) for cross-ply laminates based on the CLT. (Eslami \& Maerz, 1995) published an exact solution for the thermally induced vibrations of a cross-ply laminated plate by hygrothermal effects using the CLT. This solution is obtained by considering the total deflection as the superposition of the quasi-static and dynamic deflections.

(Malla \& Ghoshal, 1995) conducted a survey of problems caused by thermal vibrations in space structures in order to highlight the direction for future research. They found thermally induced vibration control is necessary for the new types of large and lightweight-orbiting structures. (Kim \& McManus, 1995) presented an analytical approach to obtain the transient thermal-structural response of an insulated space structure operating in Space Shuttle payload bay. The thermally induced transient motion of a structure with multi-layer thermal blankets as the control device was studied. The frequency of thermal loads can be much greater due to orbiter rotation in and out of sunlight as opposed to a spacecraft in earth orbit or even in geosynchronous orbit. A survey of recent progress in thermally induced vibrations of structures is conducted by (Johnson, Foster, Eby, \& Thornton, 1996). These papers have brought to light the understanding of thermally induced motions in spinning and non-spinning spacecraft booms and solar arrays

Recently, (Tran, Lee, \& Lim, 2007) studied the thermally induced vibration and its control for thin isotropic and laminated composite plates. The thermo-elasticity simulation is performed using the finite element method. The study showed that the structural energy flows are dependent on the material structures as well as the boundary conditions for a prescribed thermal source. (Li, Xiang, Chen, \& Xue, 2007) studied the thermally induced nonlinear vibration of practical thin-walled large-scale space structures subjected to suddenly applied thermal loading and analyzed using the finite element method. They found that in the coupled thermal-dynamic system, the stability property of the system depends on only the heat incident angle vector and damping ratios. (Gupta \& Singhal, 2010) studied the effect of non-homogeneity on thermally induced vibration of orthotropic visco-elastic rectangular plate of linearly varying thickness. They developed an analytical model using the separation of variables method, to solve the governing differential equation. They calculated Time period and deflection at different points for the first two modes of vibration for various values of temperature gradients, non-homogeneity constant, taper constant and aspect ratio. (Shen \& Hu, 2013) proposed a coupled thermal-structural model of a laminated composite plate by using the absolute nodal coordinate formulation, the transverse shear and normal deformations through element thickness. For a cantilevered flexible solar panel subjected suddenly to a solar radiation, by considering the coupling between the thermal and structural responses, they found that thermal flutter of the composite panel can be well predicted.

During the design phase of a laminated composite structure, the two most important parameters to consider are the lamination scheme and total thickness of the laminate. The effect of thermally induced displacements can be significant especially when different structural components are interconnected where spacing and clearance play an important role.

This study is a continuation of study conducted by (Akour \& Nayfeh, 2005), where they mainly studied the unidirectional ply laminate and symmetric cross ply laminate. The other cases in their investigation such as the anti-symmetric cross ply laminate are considered assuming that the coupling coefficients in the stiffness matrix are small enough to be ignored for very thin plates. The current investigation proves that ignoring such coupling even though it is small compared the other coefficients will produce misleading results. Furthermore, the present study is focused mainly on the response of laminated composite plates of different, stacking sequences, type and thickness. All the aforementioned studies are limited to laminates of single lamina (orthotropic plate) and/or single type of laminates. The studies conducted by (Akour \& Nayfeh, 2005; T. R. Tauchert, 1989; T. R Tauchert, 1990) are limited to orthotropic plates or symmetric cross-ply composite plates of constant thickness. This study is made more general in that it covers laminates of more than one lamina (effect of thickness within thin plate limits), various types of laminates (unidirectional-ply, cross-ply and angled-ply), and laminates with symmetric and anti-symmetric stacking.

\section{Finite Element Model}

Widely used composite material (T300/5208) is modeled in thin rectangular laminated composite unidirectional (05), or with symmetric cross-ply $(0,90,0,90,0)$, anti-symmetric cross-ply $(0,90,0,0,90)$, symmetric $(30,30,0,30,30)$ angle-ply, anti symmetric $(30,30,0,-30,-30)$ angle-ply, symmetric $(45,45,0,45,45)$ angle-ply, and anti-symmetric $(45,45,0,-45,-45)$ angle-ply. Also some cases are conducted for symmetric (30, $-30,-30,30)$ angle-ply and symmetric $(45,-45,-45,45)$ angle-ply. Most of the laminates are modeled as five ply laminate. 
Three different thicknesses to side length ratios were studied, $0.05,0.1$ and 0.14 . All the plates are simply supported along the four sides. Software Package ANSYS is used for all numerical calculations.

\subsection{Elements}

Two elements were chosen to make the analysis:

1. SHELL132: a 3-D layered shell element having in-plane and through-thickness thermal conduction capability (see ANSYS Release 12.0.1 help). The element has eight nodes with up to 32 temperature degrees of freedom at each node. The conducting shell element is applicable to a 3-D, steady-state or transient thermal analysis. SHELL132 generates temperatures that can be passed to structural shell elements in order to model thermal bending, as shown in figure (1).

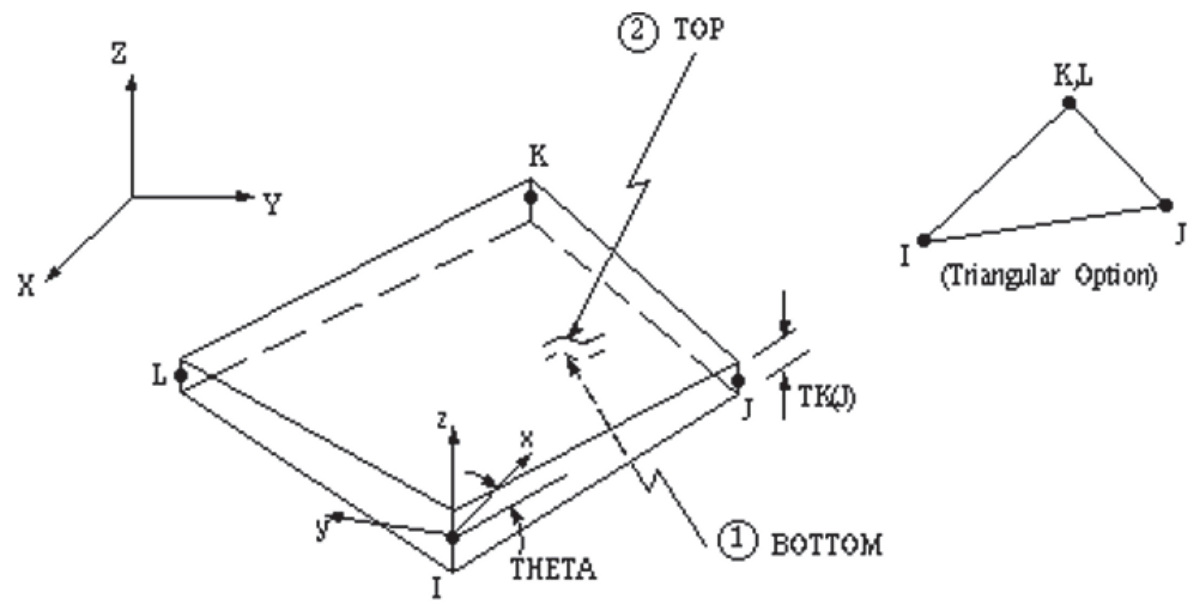

Figure 1. Illustration of shell element Shell132

2. SHELL99: a 3-D layered shell element is utilized for layered applications of a structural shell model (see ANSYS Release 12.0.1 help); it usually has a smaller element formulation time. SHELL99 allows up to 250 layers figure (2).

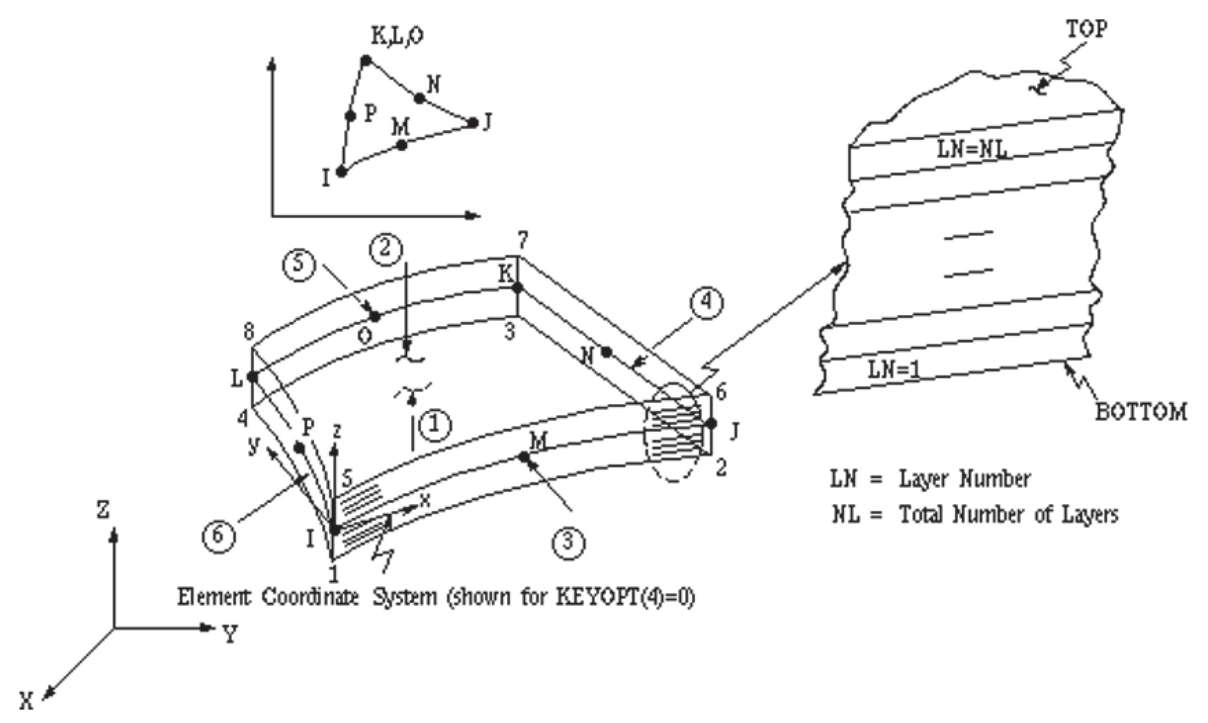

Figure 2. Illustration of shell element Shell99.

The size of the element is reduced till the changes in the results are less than $0.1 \%$. The iterative solution option is chosen to be confident of the results and the maximum number of iteration is selected to assure accuracy of results. 


\subsection{Material Properties}

Composite material utilized in this investigation is graphite epoxy laminate T300/5208. The material properties are shown in table 1 (Gibson, 2011). This material is chosen for the investigation because of its wide use in the industry.

\subsection{Loads and Boundary Conditions}

As thermal induced-vibration in laminates represents thermal-structure coupled problem, there is a special procedure that must be done on ANSYS to solve such problems. The basic procedure for the coupled environment approach is as the following:

1. Define the thermal problem.

2. Write the thermal physics file.

3. Clear boundary conditions and options.

4. Define the structural problem.

5. Write the structural physics file.

6. Read the thermal physics file.

7. Solve the thermal problem.

8. Read the structural physics file.

9. Read the temperatures from the thermal results file and insert them as loads in the structural problem.

10. Solve and post process the physics file.

Table1. Material Properties

\begin{tabular}{llll}
\hline Type & Property & $\mathrm{T} 300 / 5208$ & $\mathrm{Unit}$ \\
\hline Thermal & Density & 1600 & $\mathrm{Kg} / \mathrm{m}^{3}$ \\
& Specific Heat & 760 & $\mathrm{~J} /(\mathrm{K} * \mathrm{Kg})$ \\
& Thermal conductivity X-Direction & 0.72 & $\mathrm{~W} /(\mathrm{m} * \mathrm{~K})$ \\
\hline Structural & Modulus of elasticity X-Direction & 151 & $\mathrm{GPa}$ \\
& Modulus of elasticity Y-Direction & 10.3 & $\mathrm{GPa}$ \\
& Thermal expansion coefficient X-Direction & $3 \mathrm{e}-7$ & $1 / \mathrm{K}$ \\
& Thermal expansion coefficient Y-Direction & $2.5 \mathrm{e}-5$ & $1 / \mathrm{K}$ \\
& Major Poisson's ratio & $0.3,0.59$ & \\
& Shear modulus & 7.2 & $\mathrm{GPa}$ \\
\hline External Load & Sudden Heat Flux & 16.35 & $\mathrm{~W} / \mathrm{cm}^{2}$ \\
\hline & & &
\end{tabular}

The model is first built in ANSYS and presented by square area. Then it is meshed into equal square elements. Element shell132 is utilized in generating the thermal model the laminates. This type of elements allows the introduction of heat flux as face load. The surface 1 and surface 2 of the element are considered as bottom and top surface respectively.

The composite plate under investigation is suddenly exposed to a constant heat flux $q_{0}$ starting at $t=0$ on the top surface while the lower surface is perfectly insulated. The constant heat flux applied to the plate is assumed to be uniform over the upper surface of the plate (i.e., laminate), i.e., no temperature gradient exists in the $x-y$ plane. Based on this assumption, the only temperature gradient occurs in the $z$-direction.

Element shell99 is utilized in generating the structural model of the laminates. Simply supported boundary conditions are applied to the sides of the laminates. The laminate structure is made of multiple laminae, which are assumed to be perfectly bonded so that the structure behaves as a non-homogeneous anisotropic plate. Based on the perfect bonding assumption, no slip is allowed between the laminae and the displacements across the laminae are assumed to be continuous.

\section{Results and Discussion}

The displacement profiles of the plates are considered only for the first mode shape, following (Eslami \& Maerz, 1995; T. R Tauchert, 1990). Such a consideration is acceptable since the first mode shape is the most dominant 
one, and since we are interested only in the maximum displacement. Besides, it is known that the maximum displacement for a plate simply supported occurs when the first mode shape takes place rather than the other mode shapes given the same amount of energy. This is obvious from Figures 3 and 4 that the maximum deformation takes place at the middle of the plate and this is true for all cases contrary to the findings of (Akour \& Nayfeh, 2005). The plate is experiencing interchange of vibrations mode shape as it can be seen in Figures 3 and 4 . The system experience the third mode shape initially then the first mode shape. This is due to the laminate stacking sequence i.e. the flexural properties varies with the direction. In Figure 3, the initial peaks of the third mode shape start at opposite corners whereas in the unidirectional case Figure 4 the peaks starts close to the opposite edges of the plate. The peaks occurs along the fiber direction.

The surface temperature profile of the various types of laminates considered, i.e., unidirectional, cross-ply, and angled-ply laminates, is found to be similar to each other. A sample graph representing the temperature profile at the upper and lower surface of the laminate was plotted in Figure 5. As it can be seen, the plates contain enough lamina to prevent the lower surface from experiencing any heat rise for the time span considered in the in the investigation. The upper surface expands due to the heat supplied, while the lower surface does not experience any heat, or, temperature rise within the time period of interest. The expansion of the upper surface, while the lower one stays as it is, produces thermal moment over the whole laminate. The material properties may be considered temperature independent only over a relatively small temperature range; attention is restricted here to the response within the time period of $0<t<0.14$ (Eslami \& Maerz, 1995; T. R Tauchert, 1990). Within this time span, the temperature rise is less than $74^{\circ} \mathrm{C}$ (see Figure 5). This range of temperature rise is less than what is adopted by other researchers just to assure accuracy of the results (Eslami \& Maerz, 1995; T. R. Tauchert, 1989; T. R Tauchert, 1990; Wu \& Tauchert, 1980).

The maximum quasi-static (average), dynamic and total displacements at the plate center were presented in Figures 6 through 8. As was expected, as the plate thickness increases the total displacement decreases due to the increase in the stiffness as shown in Figure 6. This explains the increase in the frequency that is obvious in Figure 7, i.e., the frequency for thickness ratio 0.1 (Figure $7 \mathrm{~b}$ ) is higher than thickness ratio 0.05 (Figure 7a).

Figure 8 represent the quasi static displacement (average), dynamic displacement and total displacement for the cases presented in Table 2. The order of stacking based on the total displacement for low thickness ratio is different than relatively high thickness ratio as it can be seen from Figures $8 \mathrm{a}, 8 \mathrm{~b}$ and $8 \mathrm{c}$. The order is fixed as the thickness increases as it can be seen from Figure $8 \mathrm{~b}$ and $8 \mathrm{c}$. The unidirectional and, cross ply symmetric and anti symmetric laminates have the highest deformation, then comes the symmetric angle ply laminates and the anti-symmetric angle ply laminates. The difference between unidirectional and cross ply laminates is in range of $7 \%$, i.e., very close to each other. The order of these stacks in Figure 8a is Unidirectional, cross ply anti-symmetric and cross ply symmetric, whereas in Figure $8 \mathrm{~b}$ and $8 \mathrm{c}$ the order is cross ply anti-symmetric, cross ply symmetric and Unidirectional. The Symmetric angle ply $30^{\circ}, 45$ and anti- $30^{\circ}-0^{\circ}$ have almost the same deformation with variation does not exceed 2 to $3 \%$ and their deformation is less than the unidirectional and cross ply laminates. The anti -symmetric angle ply laminates comes after all these stacks in the descending order of the deformation. The symmetric angle ply laminates without middle ply are the least in the amount of deformation.

The unidirectional laminate, the cross ply anti-symmetric and symmetric have the highest amount of deformation compared to the other stacks as it can be seen in Figure 8. By examining the stiffness matrices of these stacks it is found that they have the least stiffness compared to the other stacks. For these stacks there is no stiffness coupling for the unidirectional ply laminate and the symmetric cross ply laminate (see equation 3.1 and 3.2) whereas the stiffness coupling is small for anti-symmetric cross ply i.e., the $\mathrm{B}_{11}$ and $\mathrm{B}_{22}$ are small compared to the none zero $D_{\mathrm{ij}}$ as shown in Table 3 (Gibson, 2011).

$$
\begin{aligned}
& \left\{\begin{array}{l}
N_{x} \\
N_{y} \\
N_{x y}
\end{array}\right]=\left[\begin{array}{lll}
A_{11} & A_{12} & A_{16} \\
& A_{22} & A_{26} \\
s y m & & A_{66}
\end{array}\right]\left[\begin{array}{c}
\varepsilon_{x}^{0} \\
\varepsilon_{y}^{0} \\
\gamma_{x y}^{0}
\end{array}\right\}+\left[\begin{array}{lll}
B_{11} & B_{12} & B_{16} \\
& B_{22} & B_{26} \\
s y m & & B_{66}
\end{array}\right]\left[\begin{array}{c}
\kappa_{x} \\
\kappa_{y} \\
2 \kappa_{x y}
\end{array}\right\} \\
& \left\{\begin{array}{l}
M_{x} \\
M_{y} \\
M_{x y}
\end{array}\right]=\left[\begin{array}{lll}
B_{11} & B_{12} & B_{16} \\
& B_{22} & B_{26} \\
\operatorname{sym} & & B_{66}
\end{array}\right]\left[\begin{array}{l}
\varepsilon_{x}^{0} \\
\varepsilon_{y}^{0} \\
\gamma_{x y}^{0}
\end{array}\right\}+\left[\begin{array}{lll}
D_{11} & D_{12} & D_{16} \\
& D_{22} & D_{26} \\
s y m & & D_{66}
\end{array}\right]\left[\begin{array}{c}
\kappa_{x} \\
\kappa_{y} \\
2 \kappa_{x y}
\end{array}\right\}
\end{aligned}
$$




$$
\begin{aligned}
D_{11} \frac{\partial^{4} w}{\partial x^{4}} & +4 D_{16} \frac{\partial^{4} w}{\partial x^{3} \partial y}+2\left(D_{12}+2 D_{66}\right) \frac{\partial^{4} w}{\partial x^{2} \partial y^{2}}+4 D_{26} \frac{\partial^{4} w}{\partial x^{3} \partial y}+D_{22} \frac{\partial^{4} w}{\partial y^{4}} \\
& -3 B_{16} \frac{\partial^{3} u^{o}}{\partial x^{2} \partial y}-\left(B_{12}+2 B_{66}\right) \frac{\partial^{3} u^{o}}{\partial x \partial y^{2}}-B_{26} \frac{\partial^{3} u^{o}}{\partial y^{3}}-B_{16} \frac{\partial^{3} v^{o}}{\partial x^{3}} \\
& -B_{11} \frac{\partial^{3} u^{o}}{\partial x^{3}}-\left(B_{12}+2 B_{66}\right) \frac{\partial^{3} v^{o}}{\partial x^{2} \partial y}-3 B_{26} \frac{\partial^{3} v^{o}}{\partial x \partial y^{2}}-B_{22} \frac{\partial^{3} v^{o}}{\partial y^{3}} \\
& +\rho h \frac{\partial^{2} w}{\partial t^{2}}=q_{T}(x, y)
\end{aligned}
$$

\begin{tabular}{|c|c|c|c|}
\hline name & Thickness/ Plate Width & Average / Thickness & Amplitude/ Thickness \\
\hline Uni-Laminate & 0.05 & 0.62 & 0.97 \\
\hline crossply-anti-sym & 0.05 & 0.81 & 0.76 \\
\hline crossply-sym & 0.05 & 0.78 & 0.77 \\
\hline anti-30-0 & 0.05 & 0.60 & 0.85 \\
\hline sym-30 & 0.05 & 0.65 & 0.77 \\
\hline sym-45 & 0.05 & 0.66 & 0.72 \\
\hline anti-30 & 0.05 & 0.56 & 0.70 \\
\hline anti-45 & 0.05 & 0.53 & 0.61 \\
\hline sym-30+30 & 0.05 & 0.53 & 0.56 \\
\hline sym- $45+45$ & 0.05 & 0.50 & 0.49 \\
\hline crossply-anti-sym & 0.1 & 0.201 & 0.154 \\
\hline crossply-sym & 0.1 & 0.195 & 0.150 \\
\hline Uni-Laminate & 0.1 & 0.154 & 0.170 \\
\hline sym-30 & 0.1 & 0.165 & 0.148 \\
\hline sym-45 & 0.1 & 0.168 & 0.141 \\
\hline anti-30-0 & 0.1 & 0.153 & 0.148 \\
\hline anti-30 & 0.1 & 0.144 & 0.128 \\
\hline anti-45 & 0.1 & 0.134 & 0.113 \\
\hline sym-30+30 & 0.1 & 0.135 & 0.108 \\
\hline sym $-45+45$ & 0.1 & 0.127 & 0.096 \\
\hline crossply-anti-sym & 0.14 & 0.103 & 0.063 \\
\hline crossply-sym & 0.14 & 0.100 & 0.063 \\
\hline Uni-Laminate & 0.14 & 0.079 & 0.069 \\
\hline sym-45 & 0.14 & 0.087 & 0.054 \\
\hline sym-30 & 0.14 & 0.086 & 0.054 \\
\hline anti-30-0 & 0.14 & 0.079 & 0.061 \\
\hline anti-30 & 0.14 & 0.074 & 0.051 \\
\hline anti-45 & 0.14 & 0.069 & 0.044 \\
\hline sym-30+30 & 0.14 & 0.069 & 0.043 \\
\hline sym- $45+45$ & 0.14 & 0.066 & 0.039 \\
\hline
\end{tabular}

Table 2. Summary of the results

Table 3. Summary of the stacking cases

\begin{tabular}{lll}
\hline Stacking Name & Stacking & Stiffness \\
\hline Cross ply-anti-sym & {$\left[0^{\circ} / 90^{\circ} / 0^{\circ} / 0^{\circ} / 90^{\circ}\right]$} & $B_{22} \neq 0, B_{11} \neq 0, B_{16}=0, B_{26}=0, B_{12}=0, B_{66}=0$, \\
& & $D_{11} \neq 0, D_{12} \neq 0, D_{22} \neq 0, D_{66} \neq 0, \quad D_{16}=D_{26}=0$ \\
Cross ply-Sym & {$\left[0^{\circ} / 90^{\circ} / 0^{\circ} / 90^{\circ} / 0^{\circ}\right]$} & $B_{i j}=0$ \\
& & $D_{11} \neq 0, D_{12} \neq 0, D_{22} \neq 0, D_{66} \neq 0, \quad D_{16}=D_{26}=0$
\end{tabular}




\begin{tabular}{lll}
\hline Stacking Name & Stacking & Stiffness \\
\hline Uni-Laminate & {$\left[0^{\circ} / 0^{\circ} / 0^{\circ} / 0^{\circ} / 0^{\circ}\right]$} & $B_{i j}=0$ \\
& $D_{11} \neq 0, D_{12} \neq 0, D_{22} \neq 0, D_{66} \neq 0, \quad D_{16}=D_{26}=0$ \\
Sym-30 & {$\left[30^{\circ} / 30^{\circ} / 0^{\circ} / 30^{\circ} / 30^{\circ}\right]$} & $B_{i j}=0, D_{i j} \neq 0$ \\
Sym-40 & {$\left[45^{\circ} / 45^{\circ} / 0^{\circ} / 45^{\circ} / 45^{\circ}\right]$} & $B_{i j}=0, D_{i j} \neq 0$ \\
Anti-30-0 & {$\left[0^{\circ} / 0^{\circ} / 0^{\circ} /-30^{\circ} /-30^{\circ}\right]$} & $B_{16} \neq 0, B_{26} \neq 0, \quad B_{12}=0, B_{22}=0, B_{11}=0, B_{66}=0$ \\
& & $D_{11} \neq 0, D_{12} \neq 0, D_{22} \neq 0, D_{66} \neq 0, \quad D_{16}=D_{26}=0$ \\
Anti-30 & {$\left[30^{\circ} / 30^{\circ} / 0^{\circ} /-30^{\circ} /-30^{\circ}\right]$} & $B_{16} \neq 0, B_{26} \neq 0, \quad B_{12}=0, B_{22}=0, B_{11}=0, B_{66}=0$ \\
& $, D_{11} \neq 0, D_{12} \neq 0, D_{22} \neq 0, D_{66} \neq 0, \quad D_{16}=D_{26}=0$ \\
Anti-45 & {$\left[45^{\circ} / 45^{\circ} / 0^{\circ} /-45^{\circ} /-45^{\circ}\right]$} & $B_{16} \neq 0, B_{26} \neq 0, \quad B_{12}=0, B_{22}=0, B_{11}=0, B_{66}=0$ \\
& $D_{11} \neq 0, D_{12} \neq 0, D_{22} \neq 0, D_{66} \neq 0, \quad D_{16}=D_{26}=0$ \\
Sym $-30+30$ & {$\left[30^{\circ} /-30^{\circ} /-30^{\circ} / 30^{\circ}\right]$,} & $B_{i j}=0, D_{i j} \neq 0$ \\
Sym $-45+45$ & {$\left[45^{\circ} /-45^{\circ} /-45^{\circ} / 45^{\circ}\right]$,} & $B_{i j}=0, D_{i j} \neq 0$ \\
\hline
\end{tabular}

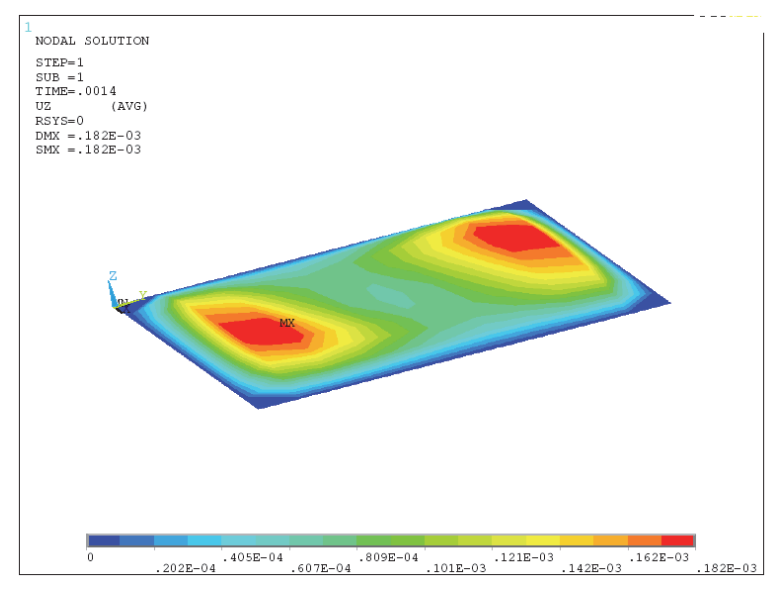

a

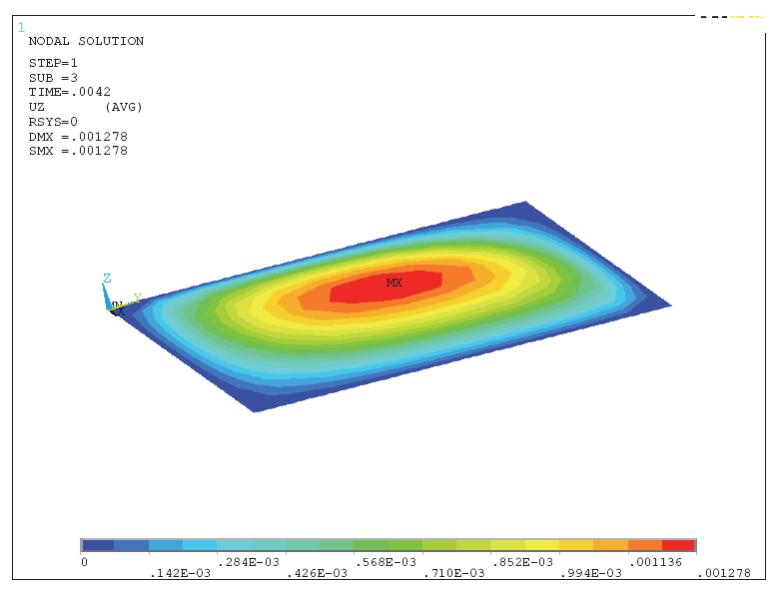

c

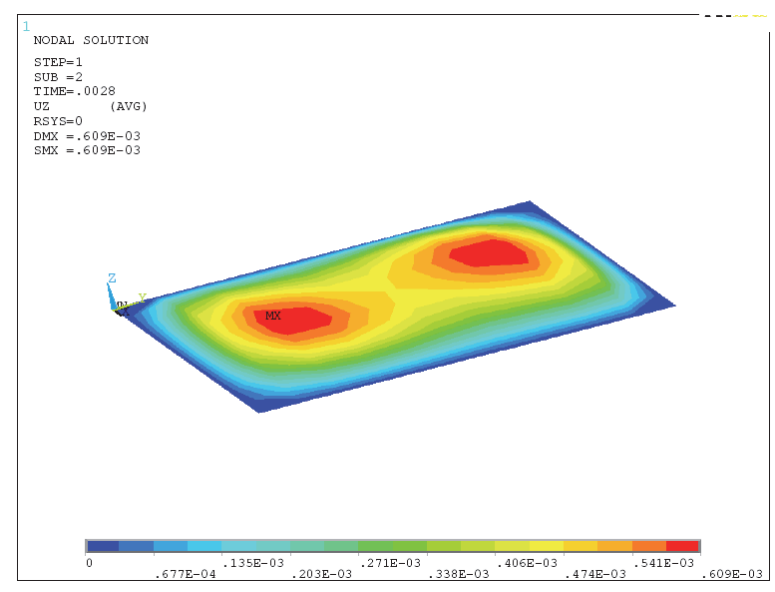

b

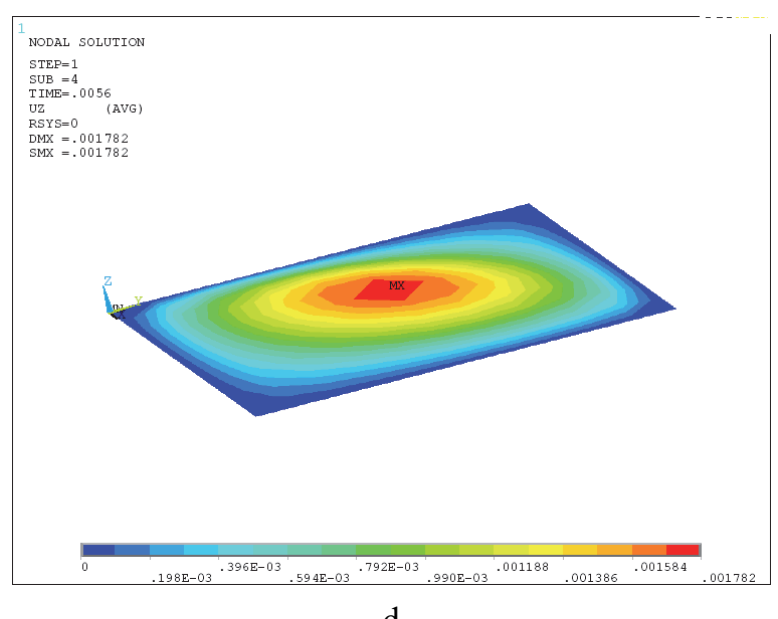

d

Figure 3. Illustration of the plate deformation sequence for symmetric-30 angle ply laminate for plate thickness to length ratio 0.05 at time a) 0.0014 , b) 0.0028 , c) 0.0042 and d) 0.0056 second 
The symmetric angle ply laminates 30 and 45 have no stiffness coupling $\left(B_{i j}=0\right)$ but all entries of $D_{i j}$ are none zero compared to unidirectional and cross ply laminates that have zero values for $\mathrm{D}_{16}$ and $\mathrm{D}_{26}$. These entries increase the overall stiffness of these stacks and therefore they have lower amount of deformation. The anti-sym-30-0 as shown in Table 3 have half of its plies unidirectional which makes it closer to the unidirectional laminate in its behavior compared to the other anti symmetric angle ply laminates.

The anti-symmetric angle-ply laminates anti-30 and anti-45 they have stiffness coupling in $\mathrm{B}_{16}$ and $\mathrm{B}_{26}$, and $\mathrm{D}_{\mathrm{ij}}$ are none zero except $D_{16}$ and $D_{26}$. This coupling contributes to the overall stiffness of the laminate.

The symmetric angle ply laminate sym- $30+30$ and sym- $45+45$ are the least in deformation. There is no coupling in this type of laminates due the none presence of the middle ply however all $\mathrm{D}_{\mathrm{ij}}$ entries are none zero.

These results deviate from those obtained by (Akour \& Nayfeh, 2005). In their investigation they have assumed that the coupling in the anti symmetric cross ply laminate and anti symmetric angle ply laminates is small and can be ignored. These assumptions lead reduction in the overall stiffness of the laminate so the unidirectional ply laminate becomes of the least deformation. From equation 3.2 it can be recognized that these stiffness entries that are ignored are good contributors to the overall behavior of the laminate response.

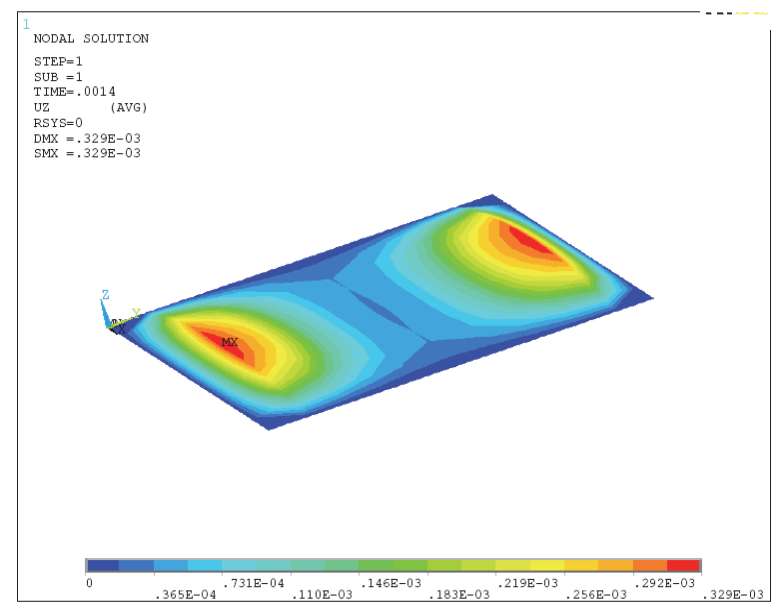

a

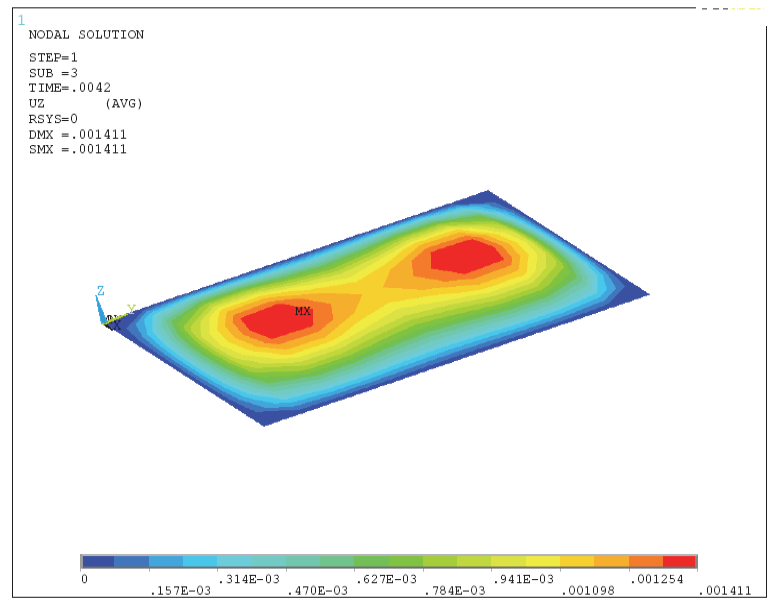

c

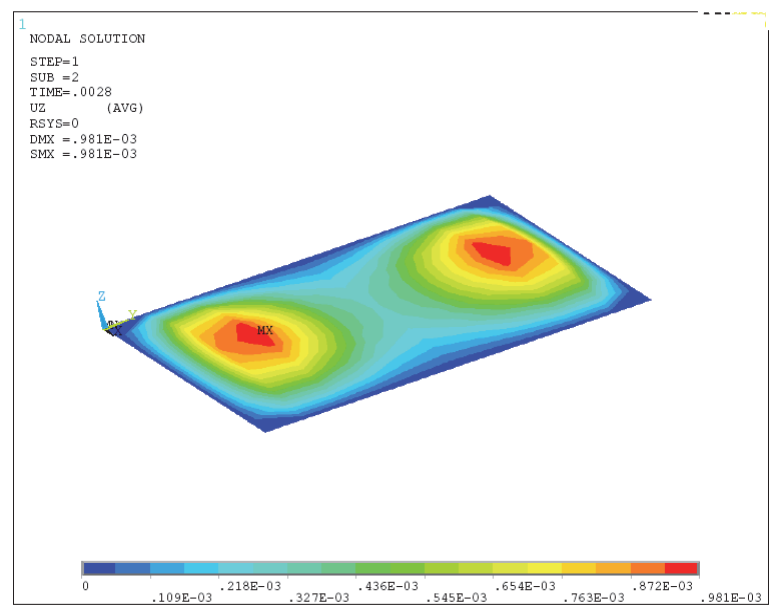

b

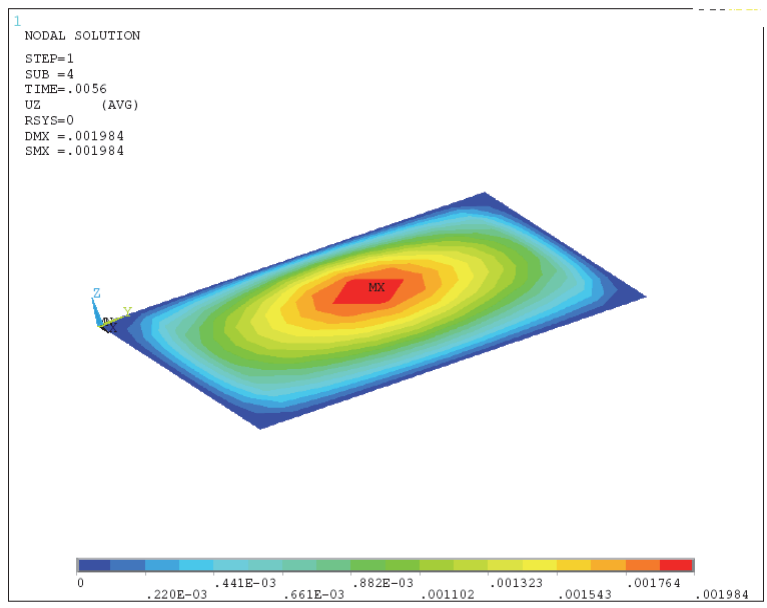

d

Figure 4. Illustration of the plate deformation sequence for Uni-Laminate for plate thickness to length ratio 0.05 at time a) 0.0014, b) 0.0028 , c) 0.0042 and d) 0.0056 second. 


\section{Conclusions}

By studying the thermally induced transverse displacements, the symmetric angle ply laminated composite plates (without middle ply) provide a better solution for the design engineer than the other stacks when attempting to minimize the transverse displacement. The maximum displacement for all laminates occurs at the middle of the plate. The behavior of the laminates based on their stacking can be classified into four groups, Unidirectional and cross ply laminates, symmetric and anti-symmetric angle ply laminates with middle ply, and symmetric angle ply laminate without middle ply. As anticipated, deformation decreases as thickness increase (stiffness increase). Also the frequency increases as the thickness increases. The systems experience mode shape interchange; initially third mode shape then first mode shape because of the anisotropic flexure.

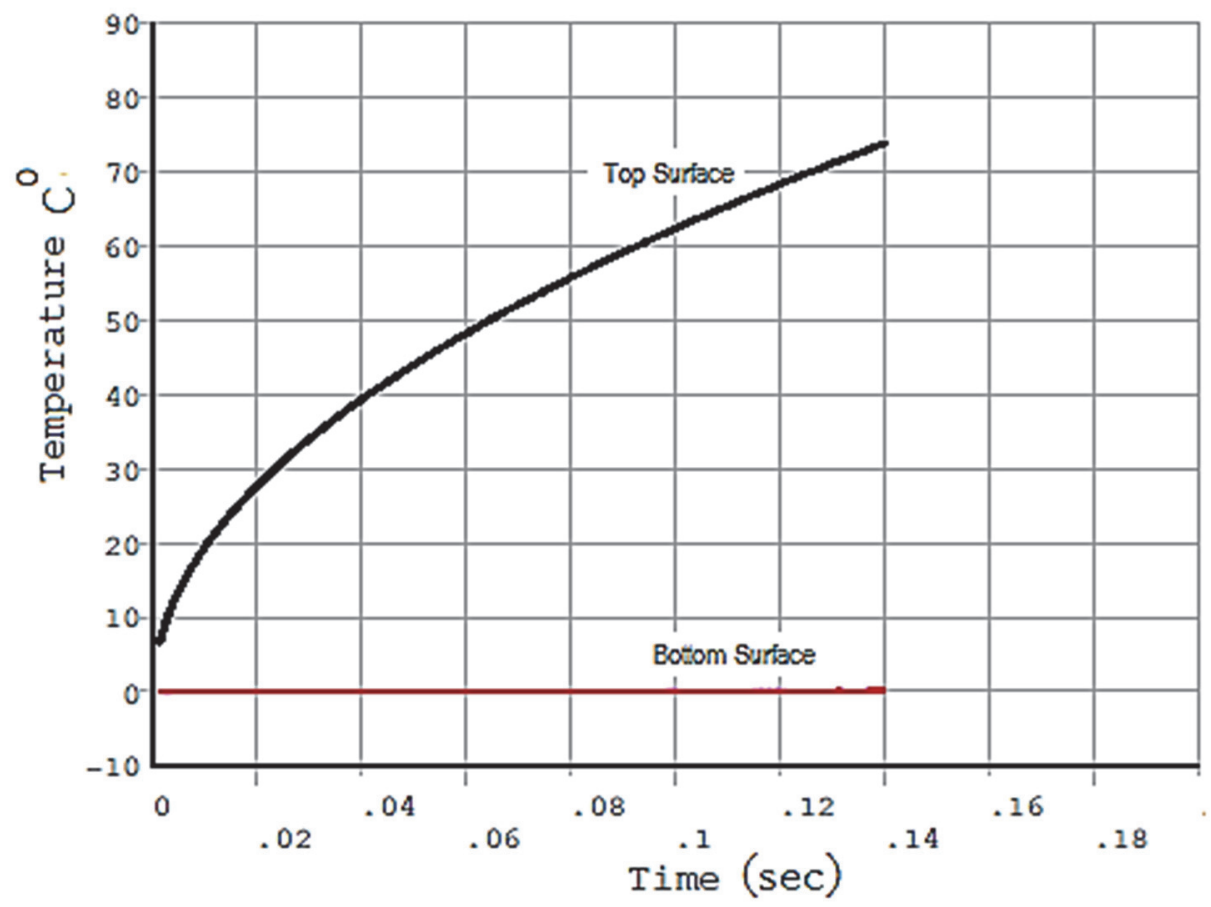

Figure 5. Sample Temperature-Time variation for top and bottom plate surfaces

Symmetrics - 30

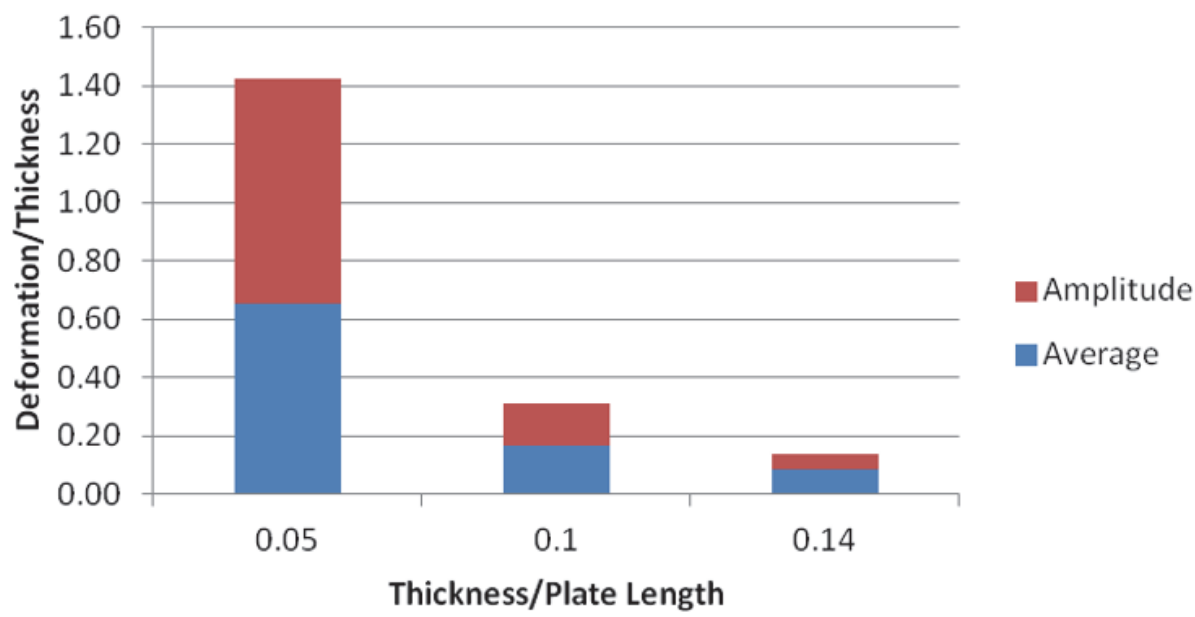

Figure 6. Illustration of the deformation with respect to the plat thickness for symmetric 30 angly ply laminte 


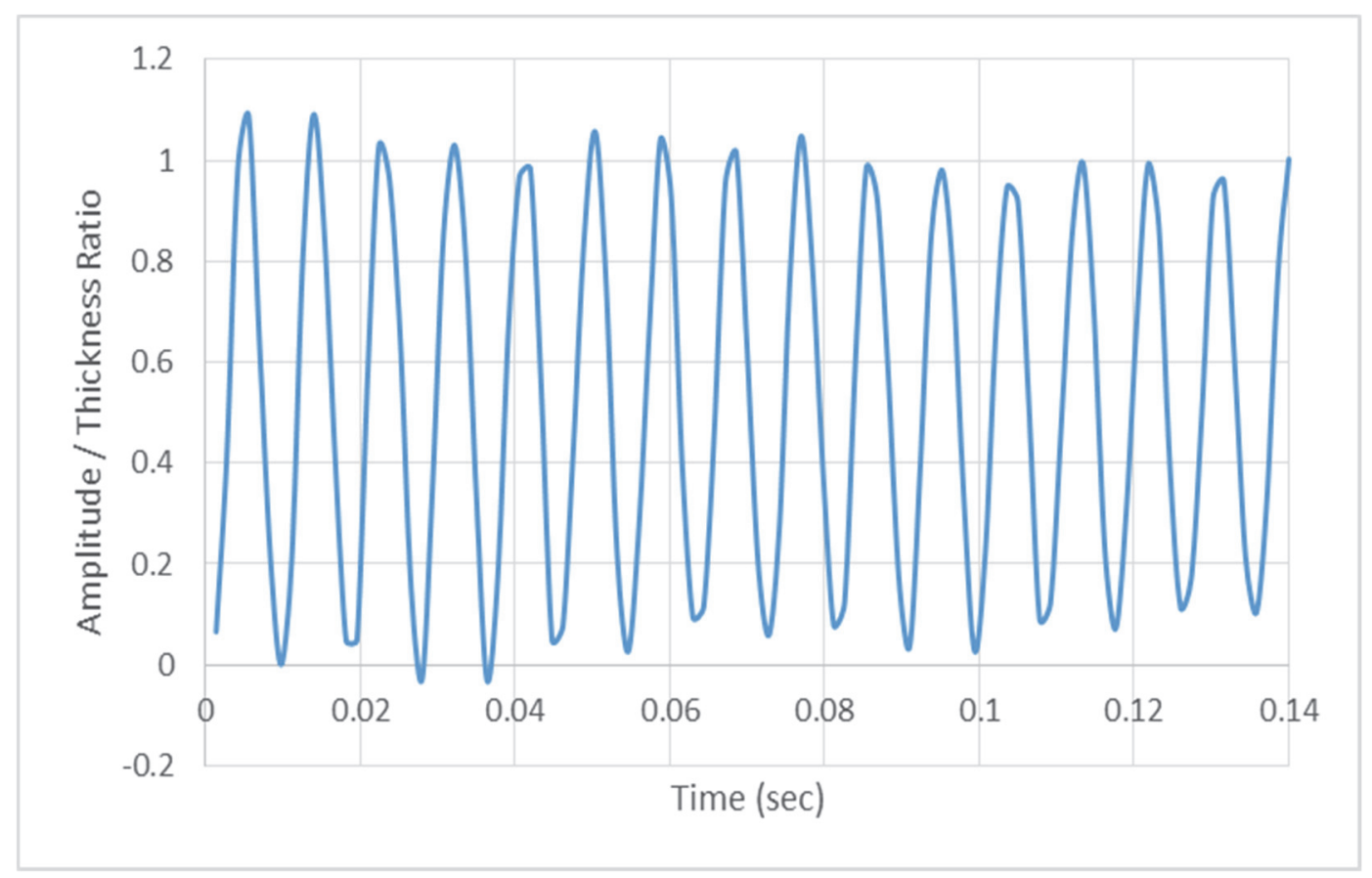

a

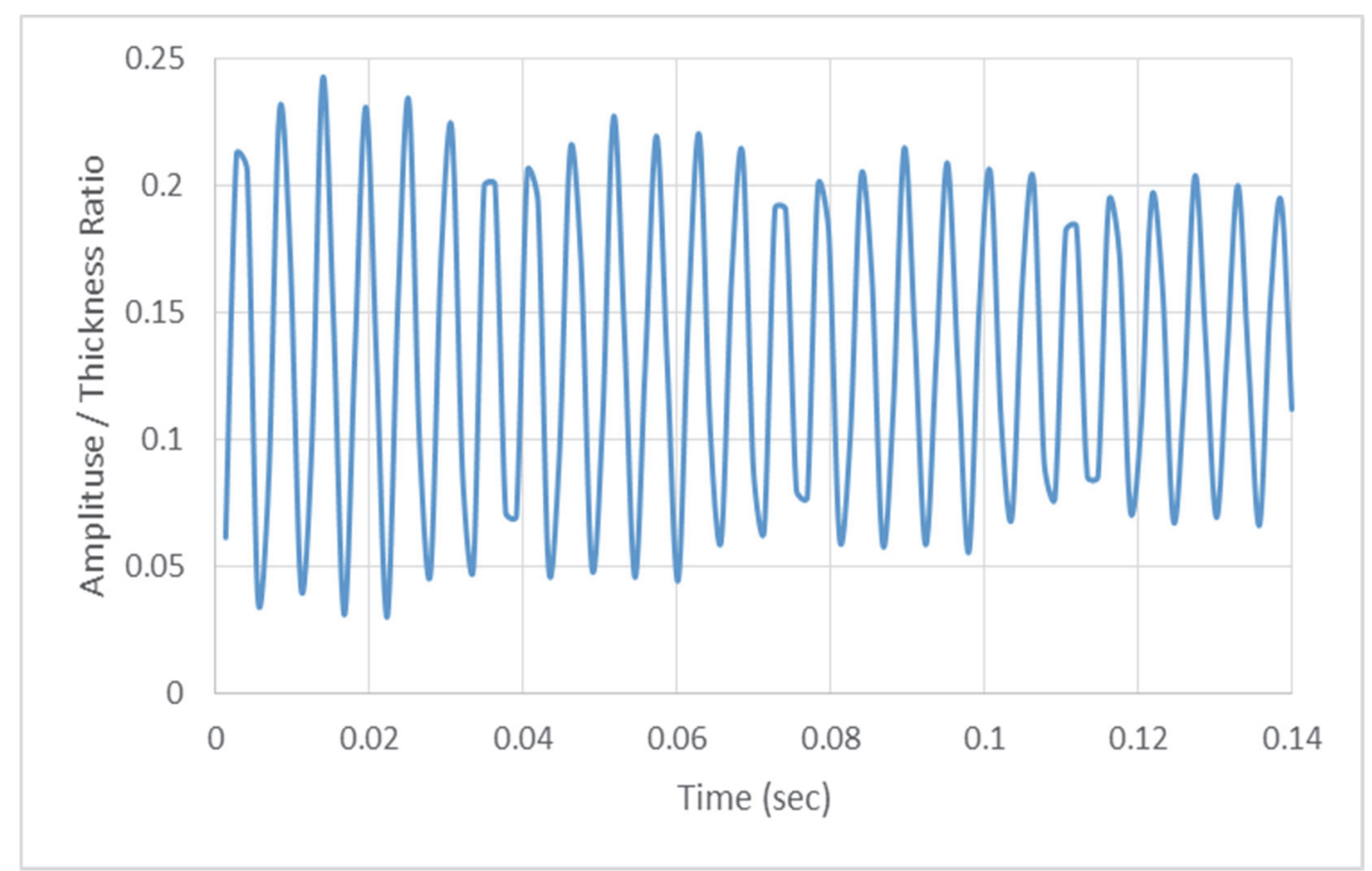

b

Figure 7. Response of symmertic 30 angle ply laminat of thickness to plat length ratio: a) 0.05 and b) 0.1 . 


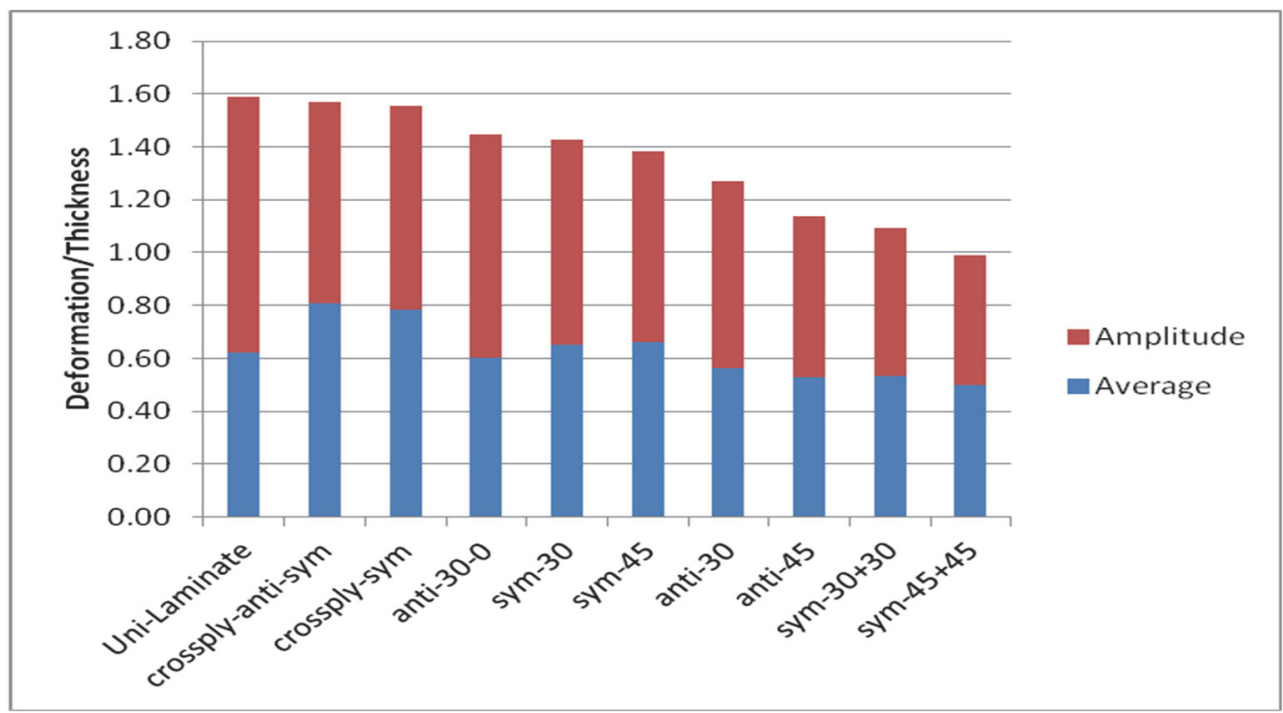

$\mathrm{a}$

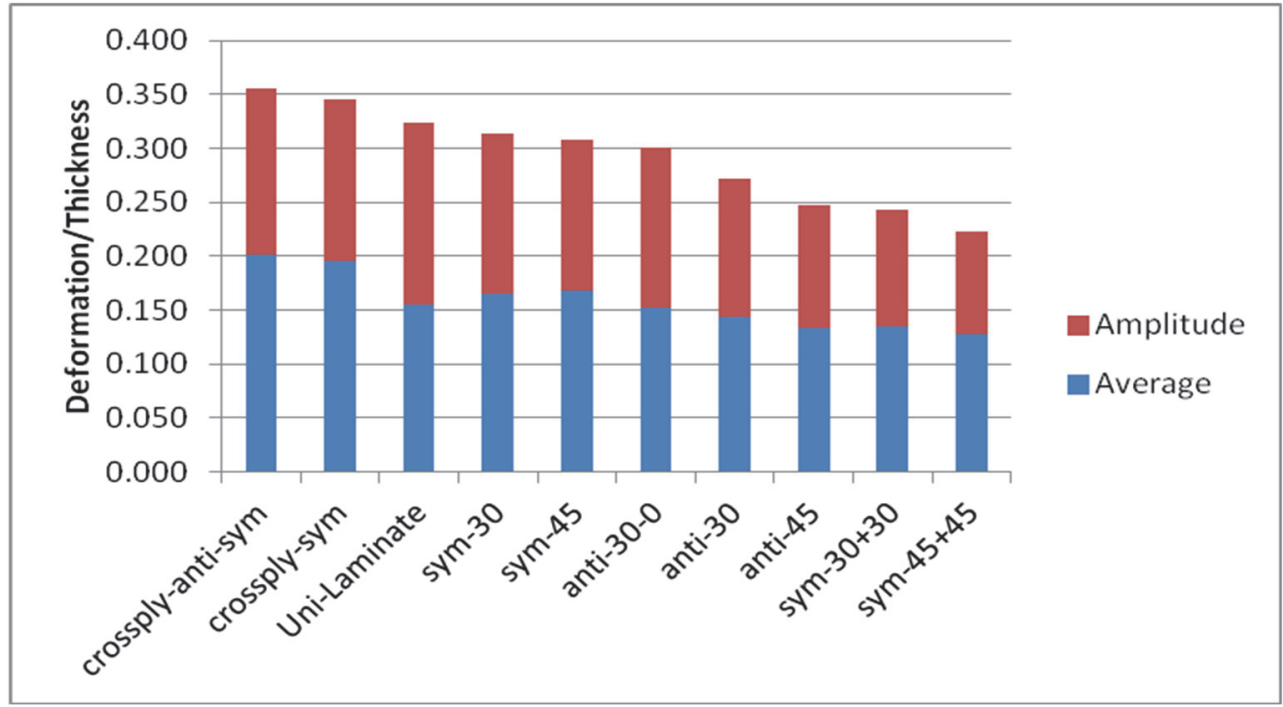

$\mathrm{b}$

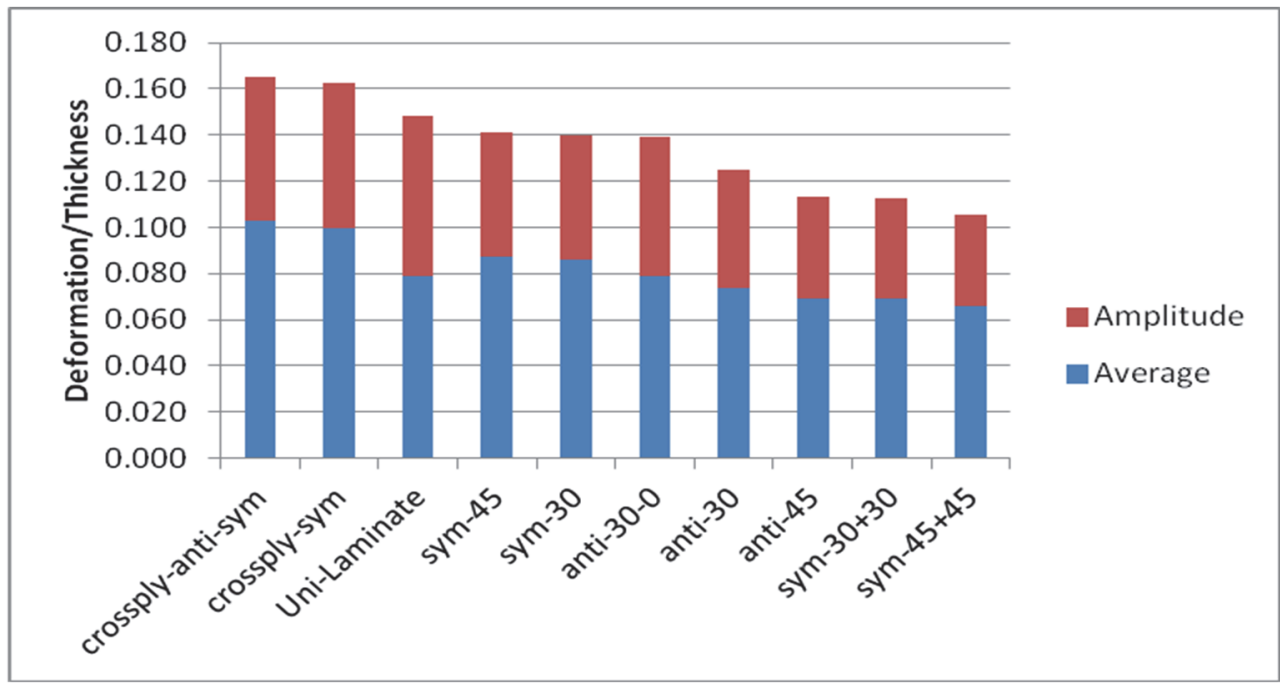

$\mathrm{c}$

Figure 8. Deformation of different laminate stacks for thickness to plate length ratio a) 0.05, b) 0.1 and c) 0.14 


\section{References}

Akour, S. N., \& Nayfeh, J. F. (2005). Thermally Induced Displacement in Simply-Supported Laminates. International Journal of Structural Stability and Dynamics, 5(1), 55-73.

Boley, B. A., \& Barber, A. D. (1957). Dynamic Response of Beams and Plates to Rapid Heating. Journal of Applied Mechanics, Trans., ASME, 79, 413-416.

Boley, B. A., \& Weiner, J. H. (1960). Theory of Thermal Stresses. New York: Wiley.

Carslaw, H. S., \& Jaeger, J. C. (1959). Conduction of Heat in Solids. London, UK: Oxford University Press.

Eslami, H., \& Maerz, S. (1995). Thermally induced vibration of a symmetric cross-ply plate with hygrothermal effects. AIAA Journal, 33(10), 1986-1988.

Gibson, R. F. (2011). Principles of Composite Material Mechanics (3rd Edition ed.). New York, USA: CRC Press.

Gupta, A. K., \& Singhal, P. (2010). Effect of Non-Homogeneity on Thermally Induced Vibration of Orthotropic Visco-Elastic Rectangular Plate of Linearly Varying Thickness. Applied Mathematics, 1(04), 326-333.

Jadeja, N. D., \& Loo, T. C. (1974). Heat Induced Vibration of a Rectangular Plate. Journal of Engineering for Industry, 96(3), 1015-1021.

Johnson, D., Foster, R. S., Eby, D. L., \& Thornton, E. A. (1996). Recent Progress in Thermally Induced Vibrations Research. Paper presented at the the Fifth International Conference on Space, New Mexico.

Kao, W. T., \& Pao, Y. C. (1976). Thermally Induced Vibration of Simply-supported Symmetric Cross-ply Plates. Paper presented at the The Southeastern Conference on Theoretical and Applied Mechanics.

Kim, Y. A., \& McManus, H. L. (1995). Transient Thermal-Structural Response of a Space Structure with Thermal Control Materials. In E. A. Thornton (Ed.), Progress in Astronautics and Aeronautics. :Aerospace Thermal Structures and Materials for a New Era (pp. 96-115): AIAA.

Li, W., Xiang, Z., Chen, L., \& Xue, M. (2007). Thermal flutter analysis of large-scale space structures based on finite element method. International Journal for Numerical Methods in Engineering, 69(5), 887-907.

Malla, R. B., \& Ghoshal, A. (1995). On Thermally-Induced Vibrations of Structures in Space. In E. A. Thornton (Ed.), Progress in Astronautics and Aeronautics: Aerospace Thermal Structures and Materials for a New Era (pp. 68-95): AIAA.

Shen, Z., \& Hu, G. (2013). Thermally Induced Vibrations of Solar Panel and Their Coupling with Satellite. International Journal of Applied Mechanics, 5(3), 142-162.

Tauchert, T. R. (1989). Thermal Shock of Orthotropic Rectangular Plates. Journal of Thermal Stresses, 12(2), 241-258.

Tauchert, T. R. (1990). Thermally induced vibration of cross-ply laminates. In V. Birman \& D. Hui (Eds.), Thermal effects on structures and materials (Vol. PVP203, pp. 15-20): ASME.

Thornton, E. A., \& Foster, R. S. (1992). Dynamic Response of Rapidly Heated Space Structures. In S. N. Atluri (Ed.), Computational Nonlinear Mechanics in Aerospace Engineering (Vol. 146): AIAA.

Timoshenko, S., \& Krieger, S. W. (1959). Theory of Plates and Shells. New York: McGraw-Hill.

Tran, T. Q. N., Lee, H. P., \& Lim, S. P. (2007). Structural intensity analysis of thin laminated composite plates subjected to thermally induced vibration. Composite Structures, 78(1), 70-83.

Wu, C. H., \& Tauchert, T. R. (1980). Thermoelastic Analysis of Laminated Plates. I: Symmetric Specially Orthotropic Laminates. Journal of Thermal Stresses, 3(2), 247-259.

Young, D. (1950). Vibration of Rectangular Plates by the Ritz Method. Journal of Applied Mechanics, Trans. ASME, 72, 448-453.

\section{Copyrights}

Copyright for this article is retained by the author(s), with first publication rights granted to the journal.

This is an open-access article distributed under the terms and conditions of the Creative Commons Attribution license (http://creativecommons.org/licenses/by/4.0/). 